\title{
Interspecific Spawning between a Recent Immigrant and an Endemic Damselfish (Pisces: Pomacentridae) in the Hawaiian Islands ${ }^{1}$
}

\author{
Karen P. Maruska ${ }^{2,3,4}$ and Kimberly A. Peyton ${ }^{5}$
}

\begin{abstract}
The Indo-Pacific damselfish Abudefduf vaigiensis (Quoy \& Gaimard, 1825) was first observed in the Hawaiian Islands in the early 1990s and is now clearly established as a breeding population in the Islands. Sightings of fish with color patterns intermediate between those of $A$. vaigiensis and the very similar endemic Hawaiian sergeant, Abudefduf abdominalis (Quoy \& Gaimard, 1825), suggest that hybridization of the two has occurred naturally. This study provides direct evidence of crossbreeding from observations and video footage of two separate spawnings in nearshore waters of $\mathrm{O}^{\prime}$ ahu and a third spawning in a public aquarium display tank. Reproductive behaviors were similar in intra- and interspecific spawning. However, one important difference was the absence of courtship by the male $A$. abdominalis toward the female $A$. vaigiensis in the interspecific spawnings. Instead, the female $A$. vaigiensis initiated spawning and the male $A$. abdominalis remained to fertilize, guard, fan, and clean the hybrid clutch along with a previous clutch until the embryos hatched. Embryos collected from one hybrid clutch showed normal embryonic development and subsequently hatched to produce viable swimming larvae. These observations represent a rare example of interspecific spawning in the damselfish family (Pomacentridae) and an exceptional opportunity to study hybridization and introgression in a wild population of coral reef fishes.
\end{abstract}

Natural interspecific hybridization is an important evolutionary process that is relatively well studied in plants, but more recently recognized to play an important role in animal evolution as well (Dowling and Secor 1997, Arnold et al. 1999). Natural hybrid-

${ }^{1}$ Support for this study was provided by Hawai'i Institute of Marine Biology and the Honolulu Chapter of Achievement Rewards for College Scientists (K.P.M.) and Hawai'i Coral Reef Initiative (K.A.P.). This is contribution no. 1254 from Hawaii Institute of Marine Biology. Manuscript accepted 28 June 2006.

${ }^{2}$ Corresponding author.

${ }^{3}$ Hawaici Institute of Marine Biology, 46-007 Lilipuna Road, Kāne'ohe, Hawai'i 96744 (phone: 808-2367466; fax: 808-236-7443; e-mail: maruska@hawaii.edu).

${ }^{4}$ Department of Zoology, University of Hawai'i at Mānoa, 2538 The Mall, Honolulu, Hawai'i 96822.

${ }^{5}$ Department of Botany and Department of Ecology, Evolution and Conservation Biology, University of Hawai'i at Mānoa, 3190 Maile Way, Honolulu, Hawai'i 96822.

Pacific Science (2007), vol. 61, no. 2:211-221

(C) 2007 by University of Hawai'i Press

All rights reserved ization can affect changes in genetic diversity and population dynamics and can lead to adaptive evolution and evolutionary diversification (Arnold et al. 1999). Studies on hybridization in the marine environment are important to address questions on the evolutionary mechanisms that lead to speciation in the sea (Rocha et al. 2005). Interspecific hybridization in fishes is commonly reported in freshwater species but relatively infrequent in marine species (Hubbs 1955). Although evidence of hybridization primarily based on body coloration patterns exists for several families of coral reef fishes (e.g., Pomacanthidae, Chaetodontidae) (Randall et al. 1977, 2001, Pyle and Randall 1994, Randall 1996), documented observations of natural interspecific spawning behaviors are rare (e.g., Moyer 1981).

The Indo-Pacific pomacentrid fish Abudefduf vaigiensis (Quoy \& Gaimard, 1825) was first observed in the Hawaiian Islands in the early 1990s (Severns and Fiene-Severns 1993, Mundy 2005) and now exists in both monospecific schools and mixed schools with the 
endemic Hawaiian sergeant (or mamo) $\mathrm{Abu}$ defduf abdominalis (Quoy \& Gaimard, 1825) (Randall 2005). Recent molecular analyses support that $A$. vaigiensis and $A$. abdominalis are separate species within the monophyletic Abudefduf genus (Quenouille et al. 2004). Based on observations of individuals with coloration patterns intermediate between those of $A$. vaigiensis and $A$. abdominalis, hybridization between the two species is hypothesized. However, both the variation in coloration patterns among individuals within a species and the similarity in coloration between the two species (Randall 1996) make it difficult to document crossbreeding based on this character alone. Thus, direct observation of spawning between the two species and molecular evidence of hybridization are required to test this hypothesis. Here we describe several observations of natural interspecific spawning between these two congeneric damselfishes.

This description is the first direct evidence of crossbreeding between the endemic $A$. abdominalis and the immigrant $A$. vaigiensis that, although separated in evolutionary time, have maintained biological and behavioral capacity to crossbreed. Further, this is the first published record of interspecific spawning behavior observed in the demersal spawning damselfish family (Pomacentridae).

\section{MATERIALS AND METHODS}

Three separate spawnings were observed by chance between a male $A$. abdominalis and a female $A$. vaigiensis. Two of these crossbreedings were observed in nearshore waters of O'ahu and the third in a display tank at the Maui Ocean Center, Wailuku, Maui. Spawning in the wild was recorded with a digital video camera in an underwater housing suspended from a dock above the nest. These crossbreedings were observed by chance because this particular area is monitored as part of a larger study on the reproductive behaviors and associated sound production of $A$. abdominalis. Comparisons of general behaviors associated with reproduction were made between these interspecific spawnings and those commonly seen in A. abdominalis conspecific spawnings. Abudefduf abdominalis intraspecific spawning behaviors used for comparison originated from two sources: (1) previously described behaviors from the studies of Helfrich (1958), Walters (1967), and Tyler (1992), and (2) observations of reproductive behaviors conducted from January 2005 to April 2006 on the southwestern side of Moku O Lo'e (Coconut Island), in Kāne'ohe Bay, O'ahu, as part of a separate study. The purpose of this paper is not to describe these intraspecific spawning observations in detail but only to use them as a comparison with behaviors observed in interspecific spawning. Thus, the interspecific spawnings were examined only for the presence or absence of the following behaviors from the male: (1) nuptial coloration (blue hue), (2) courtship motor displays such as looping or zigzag swimming in the water column to entice the female $A$. vaigiensis back to the nest to spawn, (3) prespawn aggressive chases of female, (4) tail-on-tail circling and deposition of eggs and sperm, (5) nips at female genital area, and (6) parental care (fanning, mouth picking at nest) and nest defense. The nest from the spawning at the Maui Ocean Center was checked only once 2 days later, but nests from the two spawnings in the field were monitored twice daily ( $\sim 30$ min observations over 5 days) to check for additional courtship, spawning, male nestguarding behaviors, and embryo development.

To verify fertilization and embryonic development from the interspecific spawnings, embryos were collected at two separate time periods from one of the nests in the field (interspecific spawning no. 3). Collections were made from the region of the nest that contained the hybrid embryos by free diving to gently scrape several dozen embryos into a plastic screw-cap vial at both $\sim 42 \mathrm{hr}$ and $\sim 120 \mathrm{hr}$ postfertilization. These embryos were immediately taken to the laboratory, where they were photographed with a digital camera attached to a microscope (Zeiss Axiostar 2). Embryos collected at both time periods were maintained in the laboratory until they hatched, and emergent larvae were photographed.

Interspecific spawning in fishes is hypothesized to occur when one species is rare and a 
closely related species is common (Randall et al. 1977, Moyer 1981). To test this hypothesis, fish surveys were conducted to determine the relative abundance of $A$. vaigiensis and $A$. abdominalis in the area where the interspecific spawning occurred. A total of 20 surveys were performed from June to November 2005 (about once per week) in which the total number of $A$. vaigiensis and $A$. abdominalis were counted from a surface position on a dock on Moku O Lo'e that supports a large resident Abudefduf aggregation. This site was chosen because it is the closest mixed $A$. $a b$ dominalis and $A$. vaigiensis aggregation in the area (approximately $300 \mathrm{~m}$ from the location where interspecific spawnings were observed), is in shallow water (1-2 m depth), and is sheltered from wind-driven surface waves. Fish counts were done on randomly selected days at either 0830 hours $(n=11)$ or 1400 hours $(n=9)$, and because there was no difference in the number of fish present between these time periods (Student's $t$-test, $P=0.30$ ) survey data were pooled to determine the mean percentage of $A$. vaigiensis present within the A. abdominalis-dominated group.

\section{RESULTS}

\section{Interspecific Spawning No. 1}

Spawning was observed between a male endemic $A$. abdominalis and a female IndoPacific immigrant $A$. vaigiensis at 1400 hours on 11 June 2005 on a submerged concrete pipe ( $\sim 2 \mathrm{~m}$ water depth) at Moku O Lo'e (Coconut Island). The male $A$. abdominalis in nuptial coloration spawned earlier in the morning with a female conspecific and was in the process of nest guarding benthic embryos and preparing additional substrate adjacent to the original clutch when the female $A$. vaigiensis approached. At the time of the observed interspecific spawning, there were two additional active $A$. abdominalis nests (males with clutches and nuptial coloration) within $5 \mathrm{~m}$ of the focal nest. In contrast to typical conspecific spawning events, the male $A$. abdominalis did not perform characteristic courtship behaviors (vigorous looping and zigzag swimming patterns in the water column near the nest) to entice the female A. vaigiensis into the nest for spawning. Instead, after three initial chases (rapid swim toward the female resulting in a retreat) by the guarding male, the female $A$. vaigiensis aggressively entered the nest area and began deposition of eggs on the substrate adjacent to the previously laid clutch. Upon acceptance, typical spawning behavior that involves tight tail-on-tail circling between the pair with alternating bouts of female egg deposition and male fertilization commenced (Figure 1). Throughout spawning, the male also continued to stimulate the female via nips to the genital area, clean the substrate for egg deposition, chase intruders from the nest area, and fan the original clutch.

Spawning behavior lasted approximately 2 $\mathrm{hr}$ and terminated when the female $A$. vaigiensis swam away from the nest. Subsequent observations over the following days showed that the male $A$. abdominalis did not spawn again and remained to guard both clutches of embryos. It is interesting that the same $A$. vaigiensis female attempted to enter the nest area several times on subsequent days but was chased away by the guarding male each time. In contrast, A. abdominalis females were not observed to enter the nest and attempt to spawn over that same time period. The $A$. vaigiensis eggs fertilized by the $A$. abdominalis male underwent the same developmentally associated color changes (pink to gray) seen in A. abdominalis embryos from conspecific spawnings, and the male guarded, fanned, and cleaned both clutches until the embryos hatched. When eggs are unfertilized, stop developing, or become diseased, the male $A$. $a b$ dominalis actively culls these eggs or embryos from the nest (Helfrich 1958). Thus, egg development in this hybrid clutch appeared to be normal until the embryos hatched sometime during the night of the fifth day.

\section{Interspecific Spawning No. 2}

Spawning was again observed between a male A. abdominalis and a female $A$. vaigiensis on 16 April 2006 on a vertical wall within the openocean display tank (2.8 million liters) at the Maui Ocean Center. The spawning was ob- 

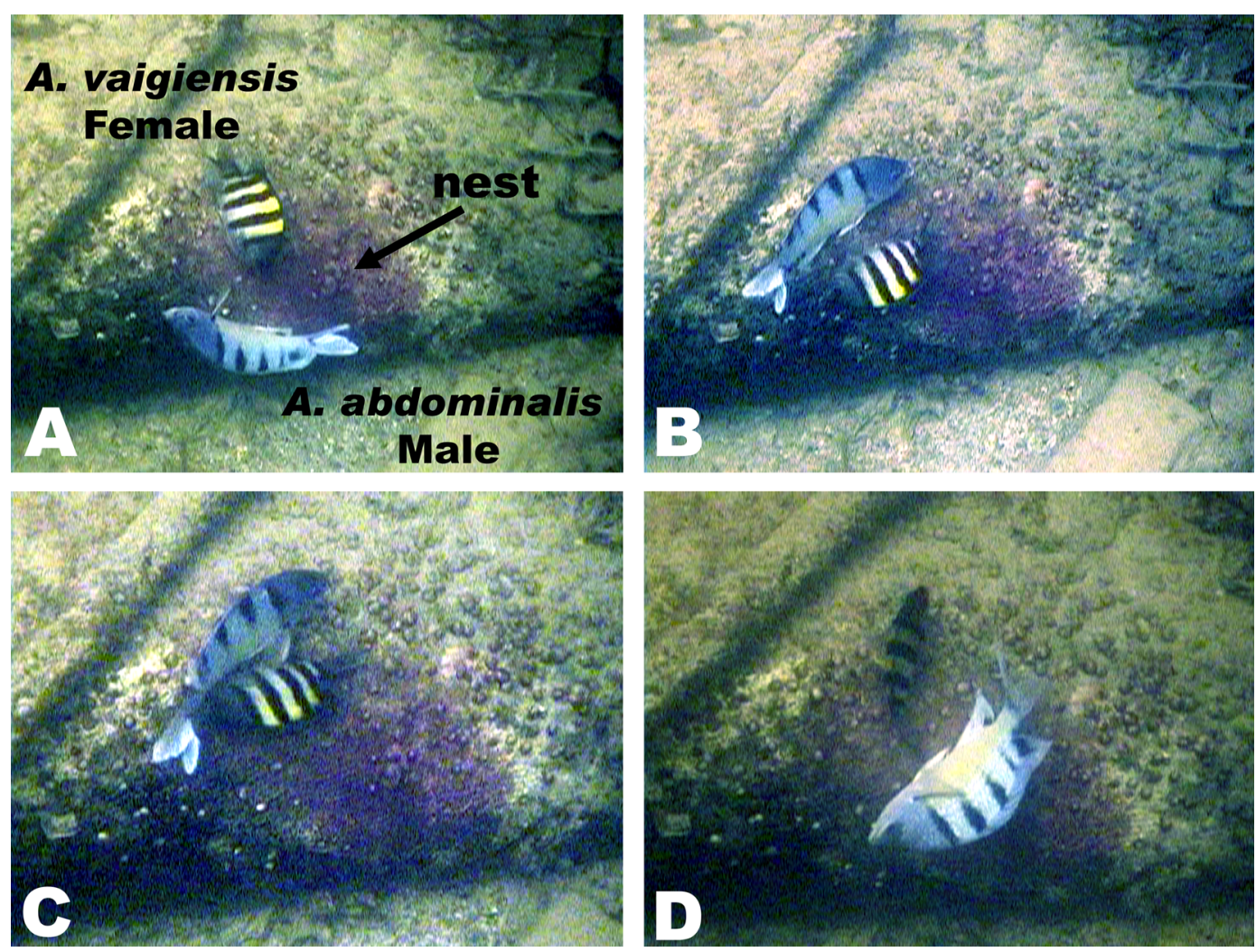

Figure 1. Male endemic Hawaiian Abudefduf abdominalis spawning with a female immigrant Indo-Pacific Abudefduf vaigiensis on a submerged concrete pipe in nearshore waters of $\mathrm{O}^{\prime}$ ahu. Photographs from a video sequence of interspecific spawning no. 1 show $(A)$ tail-on-tail circling, $(B, C)$ egg deposition by the female, and $(D)$ fertilization by the male.

served at 1430 hours when the male and female were already engaged in tight tail-ontail circling and gamete deposition. Neither the start nor finish of this spawning was observed, so details on whether or not courtship displays were present or duration of spawning are not available in this case. The spawning was observed for $\sim 45 \mathrm{~min}$, during which male nuptial coloration, nips at the female, chases of intruders, substrate cleaning, tailon-tail circling, and gamete deposition evidenced by protrusion of genital papilla were all observed. This nest was checked 2 days later and the male was observed to guard and fan the clutch. Due to the location of this nest, the total number of clutches and degree of embryonic development could not be determined.

\section{Interspecific Spawning No. 3}

The third interspecific spawning was also between a male $A$. abdominalis and a female $A$. vaigiensis that occurred on 24 April 2006 on a vertical concrete piling ( $\sim \mathrm{m}$ water depth) (Figure 2) within $3 \mathrm{~m}$ of the site described in interspecific spawning no. 1 . At the time of this interspecific spawning, there were also three additional active $A$. abdominalis nests (males with clutches, nuptial coloration, and actively courting) within $5 \mathrm{~m}$ of the focal nest. The interspecific spawning began at 

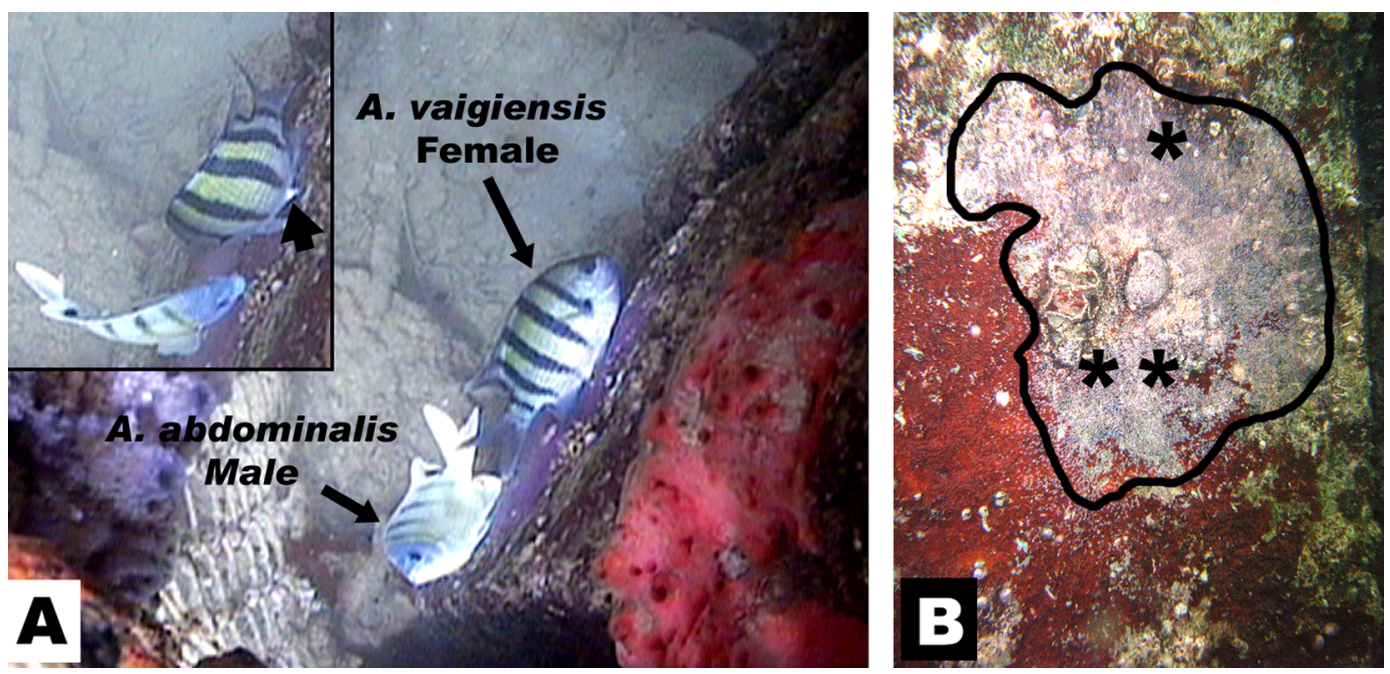

Figure 2. Interspecific spawning no. 3 between a male Abudefduf abdominalis and female Abudefduf vaigiensis on a concrete piling in nearshore waters of $\mathrm{O}^{\prime}$ ahu. $(A)$ Tail-on-tail circling during spawning between the pair. Inset shows the protruded genital papilla (arrowhead) of the female during egg deposition. (B) Photograph of the nest (outlined) at $\sim 42 \mathrm{hr}$ postfertilization. Asterisk $\left.{ }^{*}\right)$ indicates location of the interspecific clutch where embryos were collected, and the double asterisk $(* *)$ indicates the location of the previously existing clutch.

1445 hours and lasted approximately $2 \mathrm{hr}$. The male $A$. abdominalis in nuptial coloration was in the process of nest guarding a single clutch of recently deposited eggs (pink), preparing additional spawning substrate, and actively performing courtship displays to passing $A$. abdominalis females. While the male performed a looping courtship display toward several female $A$. abdominalis swimming above the nest, the female $A$. vaigiensis entered the nest area from the opposite direction of the male's attention (behind the concrete piling) and thus was not directly courted by the male. Similar to interspecific spawning no. 1, there were two initial chases by the guarding male, but the female $A$. vaigiensis remained in the nest area and began deposition of eggs on the substrate adjacent to the previously laid clutch. After acceptance, typical spawning behavior commenced as described earlier for spawning no. 1 . In addition to stimulation of the female via nips to the genital area, cleaning the substrate for egg deposition, chasing intruders from the nest area, and fanning the original clutch, the male also continued to perform courtship displays toward passing female $A$. abdominalis. On occasion, a female $A$. abdominalis followed him back and entered the nest area but left within several seconds of arrival at the nest where the $A$. vaigiensis female was already depositing eggs. Spawning terminated when the female A. vaigiensis abruptly swam away from the nest.

Similar to spawning no. 1 , the male $A$. $a b$ dominalis did not spawn again. The $A$. vaigiensis eggs fertilized by the $A$. abdominalis male underwent the same developmentally associated color changes (pink to gray) seen in spawning no. 1, and the male remained to guard, fan, and clean both clutches until the embryos hatched. Collections of embryos from this hybrid clutch show that these embryos developed normally and hatched successfully on the evening of the sixth day. Embryos collected at both $\sim 42$ and $\sim 120 \mathrm{hr}$ postfertilization (Figure 3) had all the same characteristics described by Helfrich (1958) for embryological development in conspecific A. abdominalis nests and hatched in the labo- 

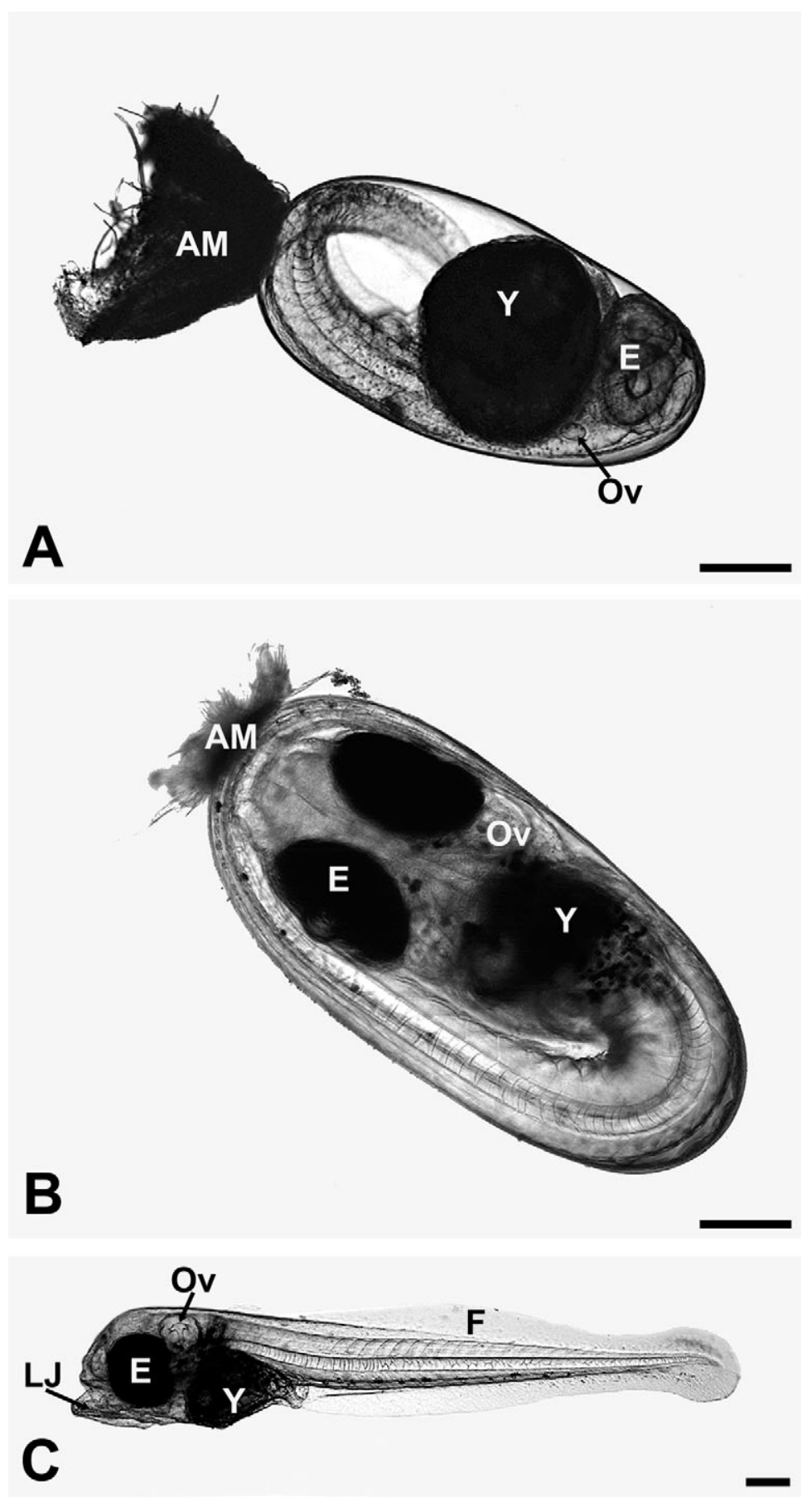

FIGURE 3. Embryos collected from interspecific spawning no. 3 between a male Abudefduf abdominalis and female Abudefduf vaigiensis. (A) Embryo at $\sim 42 \mathrm{hr}$ postfertilization shows a large yolk sac $(\mathrm{Y})$ and clear development of the eye $(\mathrm{E})$, otic vesicle $(\mathrm{Ov})$, and body somites. The adhesive membrane (AM) attaches the embryo to the substrate. $(B)$ Embryo at $\sim 120 \mathrm{hr}$ postfertilization is much larger and the tail can be seen to wrap around the head, the yolk sac is diminished, the eyes are large and pigmented with clear lens development, and blood flow from the beating heart is visible throughout the body. $(C)$ Larvae 1 day after hatching in the laboratory have a long transparent body with a continuous fin fold (F) and visible jaw (LJ, lower jaw) development. Scale bars $=150 \mu \mathrm{m}(A, B) ; 200 \mu \mathrm{m}(C)$. 


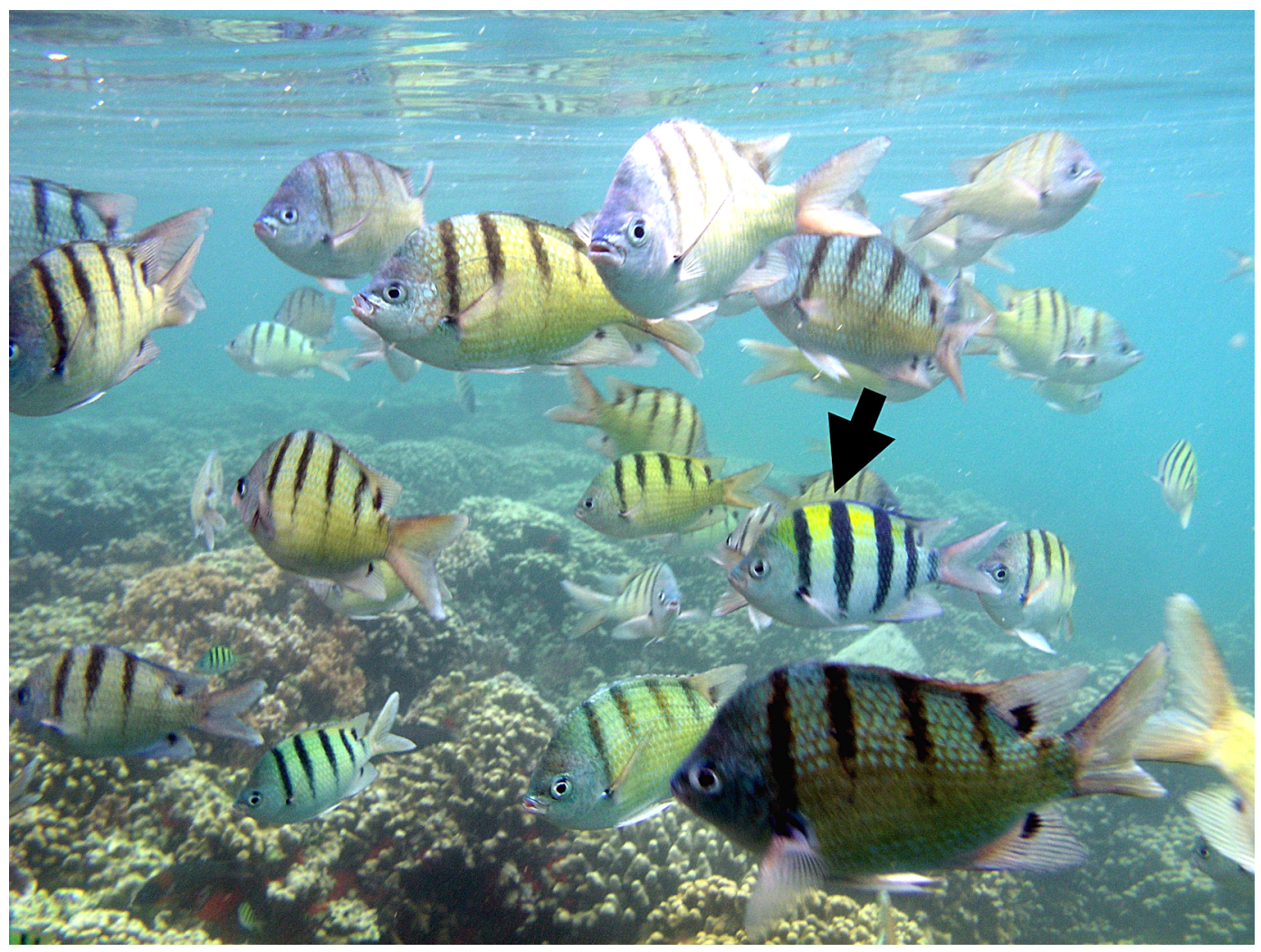

Figure 4. Aggregation of Abudefduf abdominalis at Moku O Lo'e in Kāne'ohe Bay, where fish surveys were conducted. Abudefduf vaigiensis (arrow) coexists with $A$. abdominalis in mixed schools but represents only $1-5 \%$ of the aggregation at this site.

ratory to produce viable swimming larvae (Figure 3). Embryos and larvae were preserved in ethanol for future genetic analyses.

\section{Fish Surveys}

Fish surveys conducted in the months following the first interspecific spawning at a single site off Moku O Lo'e that has a resident colony of 75-150 Abudefduf individuals showed that $A$. vaigiensis represents approximately $1-5 \%$ (mean $=3.0 \pm 0.9 \% \mathrm{SD}$ ) of this $A$. abdominalis-dominated aggregation (Figure 4).

\section{DISCUSSION}

This study is the first direct evidence of spawning between the endemic $A$. abdominalis and immigrant $A$. vaigiensis. Reproductive behavior during these interspecific spawnings was similar to that observed in conspecific spawnings (i.e., five of the six reproductive behaviors were observed in both intra- and interspecific spawning). However, one important difference was the absence of male courtship displays such as zigzag swimming and looping toward the female $A$. vaigiensis in the interspecific spawnings. The reason for lack of male courtship behavior is unknown, but several explanations are plausible. First, if the female $A$. vaigiensis ova were in a stage of advanced maturation, her high motivation to spawn may have reduced the need for male courtship behavior. Observations of $A$. $a b-$ dominalis intraspecific spawning always involved some courtship motor patterns by the male (e.g., looping, zigzag swimming), but we 
cannot discount the possibility that a gravid conspecific would have resulted in the same absence of courtship behavior seen in spawning no. 1. Although there is evidence that male courtship behaviors are absent or reduced just before spawning in some damselfishes that maintain permanent territories (Goulet 1997, Karino and Kuwamura 1997), this is rarely the case for the temporary territorial Abudefduf species that always show at least some level of courtship display (Helfrich 1958, Thresher 1984, Tyler 1992). In fact, in interspecific spawning no. 3 , the male was actively courting other female $A$. abdominalis but did not court the $A$. vaigiensis that entered the nest. Nevertheless, the observed absence of male courtship may be a real difference between inter- and intraspecific spawning, or possibly related to female readiness. Second, male $A$. abdominalis do not actively court $A$. vaigiensis females because they are heterospecific. In fact, actively courting male $A$. abdominalis trying to lead a conspecific female to the nest often aggressively chase female $A$. vaigiensis that try to approach their nests (pers. obs.). Thus it is possible that the initiation of spawning and egg deposition provides some sign stimulus (e.g., visual, chemical, mechanosensory, or auditory cue) to the male that triggers the action patterns for spawning such as tail-on-tail circling, nips at the female, and sperm deposition. Thus once the female aggressively and successfully reached the nest site and began egg deposition, the male was stimulated to follow. This behavior where the female of a less-abundant species initiates spawning was also observed in an example of angelfish interspecific spawning (Moyer 1981). Third, it is possible in spawning no. 1 that the male was not yet ready for a subsequent spawning (e.g., had not cleaned and prepared enough additional substrate for egg deposition) after his earlier spawning. Future observations are necessary to test whether or not the absence of courtship behavior is common in interspecific spawning among damselfishes.

Reproduction within colonial nesting damselfishes is often synchronized such that the majority of spawning occurs within a few days (Thresher 1984, Tyler 1992, Danilowicz
1995, Mann and Lobel 1995). In our study, the immigrant $A$. vaigiensis appeared to synchronize their reproductive readiness with that of the resident endemic $A$. abdominalis population. Spawning patterns in A. abdominalis are correlated on a large temporal scale with environmental cues such as lunar cycles, amount of freshwater input from stream discharge, and food abundance (Helfrich 1958, Tyler 1988, Tyler and Stanton 1995). On a smaller temporal scale within individual colonies, spawning is further synchronized so that there are multiple active nests at the same time (Tyler 1988, 1992). The mechanism for this fine-scale synchrony is unknown but may involve intracolonial supplemental cues such as increased motor, sonic, and color patterns associated with courtship behaviors from neighboring males. In addition to the interspecific spawnings observed here, there were other concurrently active nests within the study area on Moku O Lo'e during both interspecific spawnings no. 1 and 3. Studies on A. abdominalis in Kāne'ohe Bay indicate that reproductive fitness is maximized primarily by reduced egg predation found in synchronized colonial nesting populations (Tyler 1995). It is interesting that we also observed a male $A$. vaigiensis spawning with a female $A$. vaigiensis at the time of interspecific spawning no. 3, which indicates that the local breeding population of this species may respond to the same cues that synchronize spawning in A. abdominalis. Thus it is possible that reproductive synchronization of the few A. vaigiensis individuals within a colony of $A$. abdominalis may increase their reproductive fitness and improve their chances of successful spawning.

Interspecific spawning in fishes often occurs in situations where one species is rare and a closely related species is common (Randall et al. 1977, Moyer 1981). One hypothesized explanation for the fact that these interspecific spawnings generally occur between females of the rare species and males of the common species is the high energetic costs of egg versus sperm production (Trivers 1972). However, this hypothesis may apply only to fish species that spawn in the water column, such as butterflyfishes and angel- 
fishes, that do not expend additional energy on parental care. In fact, the most frequent occurrences of hybrids in marine fishes are found in these two families (Chaetodontidae and Pomacanthidae) (Clavijo 1985, Pyle and Randall 1994, McMillan and Palumbi 1995, Randall 2005), and accounts of hybridization in species with demersal spawning and parental care such as damselfishes are rare. Reproductive success of a parental male involves trade-offs between parental, mating, and somatic efforts that are influenced by many variables such as clutch size, availability of fertile females, predation pressure, and food availability (Magrath and Komdeur 2003). Male damselfish may not suffer any measurable decrease in reproductive fitness from occasional interspecific spawnings because they can invest simultaneously in parental and mating efforts. Guarding an additional hybrid clutch within a nest may be only a minor cost for the male if sperm and nest space are not limited. Alternatively, because female damselfish species often prefer nests that already contain eggs (Thresher 1984, Tyler 1992, Goulet 1997, 1998), the male A. abdominalis may even increase future reproductive success through care of the hybrid clutch. Thus if conditions are suitable, the potential for frequent crossbreeding and hybridization between these species may be substantial.

The impact of introduced species is often detrimental to native or endemic marine populations (Carlton 2000). The historical geographic range of $A$. vaigiensis is the IndoPacific from South Africa and the Red Sea to Indonesia, Japan, the Ogasawara Islands, Australia, Micronesia, the Line Islands, the Tuamotu Archipelago, and the Marquesas (Mundy 2005, Randall 2005). However, in addition to the recent reports in the Hawaiian Islands (Severns and Fiene-Severns 1993, Mundy 2005, Randall 2005), new records of this species were noted in areas such as New Zealand (Francis et al. 1999) and the Mediterranean Sea (Goren and Galil 1998). Rafting via natural substrates can be a dispersal mechanism for some marine species (see Thiel et al. [2005] for review), and juvenile $A$. vaigiensis are documented as a common member of drift algae assemblages (Nakata et al. 1988) and flotsam-associated ichthyofauna in the western Pacific (Kimura et al. 1998). The hypothesized vector for the dispersal of $A$. vaigiensis to the isolated Hawaiian Archipelago (and possibly other areas) is ghost fishing nets and gear (Mundy 2005). Thus, the appearance of $A$. vaigiensis is documented as a "natural" recruitment of a species to the Hawaiian Islands via anthropogenic vectors (Mundy 2005). The abundant supply of marine debris in the Northwestern Hawaiian Islands is a conservation concern, with more than 500 tons of derelict fish gear and other synthetic materials removed in the past decade (Timmers et al. 2005). For organisms such as juvenile $A$. vaigiensis, these drifting, transitory islands of flotsam may serve as a vector to invade new areas much like ship bottoms have for fouling organisms.

Abudefduf vaigiensis has appeared in increasing numbers in Hawai' $i$ since the early 1990s and can even be found displayed with $A$. abdominalis in public aquaria. Thus the fate of this species and the endemic A. abdominalis in the Hawaiian Islands is questioned (Mundy 2005). Abudefduf vaigiensis seems to be a more aggressive competitor than $A$. $a b$ dominalis (K.P.M., pers. obs.), and A. vaigiensis was also documented to outcompete the Pacific gregory damselfish Stegastes fasciolatus (Ogilby, 1889) for nesting substrate on reefs in Taiwan, even with the associated trade-off of egg predation (Jan 1995). Thus direct competition for food and nesting substrate between cohabitating $A$. abdominalis and $A$. vaigiensis is a concern. In addition, spawning colonies of $A$. vaigiensis are already established in several different locations within the main and Northwestern Hawaiian Islands (Severns and Fiene-Severns 1993, Mundy 2005), and putative $A$. abdominalis $\times A$. vaigiensis hybrids (based on intermediate coloration patterns) have been reported by local dive enthusiasts and fish biologists in Hawai' $i$ in recent years. Results from our study support the hypothesis that these Abudefduf species can hybridize and produce viable newly hatched larvae. The crossbreeding potential of these two species represents a unique "natural experiment" opportunity to observe and investigate introgression essentially from the 
beginning within wild fish populations. Thus the frequency of occurrence and genetic consequence of hybridization between these congeners warrants investigation.

\section{ACKNOWLEDGMENTS}

We thank Frank G. Stanton and John E. Randall for pertinent information, and Richard L. Pyle, Lisa A. Privitera, Timothy C. Tricas, and two reviewers for helpful comments on an early draft of the manuscript.

\section{Literature Cited}

Arnold, M. L., M. R. Bulger, J. M. Burke, A. L. Hemphl, and J. H. Williams. 1999. Natural hybridization: How low can you go and still be important? Ecology 80:371-381.

Carlton, J. T. 2000. Global change and biological invasions in the oceans. Pages $31-$ 53 in H. A. Mooney and R. J. Hobbs, eds. Invasive species in a changing world. Island Press, Covelo, California.

Clavijo, I. E. 1985. A probable hybrid butterflyfish from the western Atlantic. Copeia 1985 (1): 235-238.

Danilowicz, B. S. 1995. Spatial patterns of spawning in the coral-reef damselfish Dascyllus albisella. Mar. Biol. (Berl.) 122:145155.

Dowling, T. E., and C. L. Secor. 1997. The role of hybridization and introgression in the diversification of animals. Annu. Rev. Ecol. Syst. 28:593-619.

Francis, M. P., C. J. Worthington, P. Saul, and K. D. Clements. 1999. New and rare tropical and subtropical fishes from northern New Zealand. N. Z. J. Mar. Freshwater Res. 33:571-586.

Goren, M., and B. S. Galil. 1998. First record of the Indo-Pacific coral reef fish Abudefduf vaigiensis (Quoy and Gaimard, 1825) in the Levant. Isr. J. Zool. 44:57-59.

Goulet, D. 1997. Reproductive behavior and spawning success of female Amblyglyphidodon leucogaster (Pisces: Pomacentridae) from the Red Sea. Environ. Biol. Fishes 50:49-60.

1998. Spawning success in the damselfish Amblyglyphidodon leucogaster: The influence of eggs in the nest. Anim. Behav. $55: 651-664$.

Helfrich, P. 1958. The early life history and reproductive behavior of the maomao, Abudefduf abdominalis (Quoy and Gaimard). Ph.D. diss., University of Hawai'i at Mānoa, Honolulu.

Hubbs, C. L. 1955. Hybridization between fish species in nature. Syst. Zool. 4:1-20.

Jan, R. Q. 1995. What do the sergeant major Abudefduf vaigiensis lose from nesting in the territories of Pacific gregory Stegastes fasciolatus. Zool. Stud. 34:131-135.

Karino, K., and T. Kuwamura. 1997. Plasticity in spawning visits of female damselfish, Stegastes nigricans: Effect of distance to mates. Behav. Ecol. Sociobiol. 41:55-59.

Kimura, M., Y. Morii, T. Kuno, H. Nishida, H. Yoshimura, Y. Akishige, and T. Senta. 1998. Flotsam ichthyofauna in the tropical water of the West Pacific Ocean. Bull. Fac. Fish. Nagasaki Univ. 79:9-20.

Magrath, M. J. L., and J. Komdeur. 2003. Is male care compromised by additional mating opportunity? Trends Ecol. Evol. 18:424-430.

Mann, D. A., and P. S. Lobel. 1995. Passive acoustic detection of sounds produced by the damselfish, Dascyllus albisella (Pomacentridae). Bioacoustics 6:199-213.

McMillan, W. O., and S. R. Palumbi. 1995. Concordant evolutionary patterns among Indo-West Pacific butterflyfishes. Proc. R. Soc. Lond. B Biol. Sci. 260:229-236.

Moyer, J. T. 1981. Interspecific spawning of the pygmy angelfishes Centropyge shepardi and Centropyge bispinosus in Guam. Micronesica 17:119-124.

Mundy, B. C. 2005. Checklist of the fishes of the Hawaiian Archipelago. Bishop Mus. Bull. Zool. 6.

Nakata, H., H. Takeuchi, and T. Hirano. 1988. A field experiment with drifting hoop nets to collect the small fish gathering around drift algae. Bull. Jpn. Soc. Sci. Fish. 54:1899-1906.

Pyle, R. L., and J. E. Randall. 1994. A review of hybridization in marine angelfishes (Perciformes: Pomacanthidae). Environ. Biol. Fishes 41:127-145.

Quenouille, B., E. Bermingham, and S. 
Planes. 2004. Molecular systematics of the damselfishes (Teleostei: Pomacentridae): Bayesian phylogenetic analyses of mitochondrial and nuclear DNA sequences. Mol. Phylogenet. Evol. 31:66-88.

Randall, J. E. 1996. Shore fishes of Hawai'i. University of Hawai'i Press, Honolulu.

- 2005. Reef and shore fishes of the South Pacific: New Caledonia to Tahiti and the Pitcairn Islands. University of $\mathrm{Ha}$ wai'i Press, Honolulu.

Randall, J. E., G. R. Allen, and R. C. Steene. 1977. Five probable hybrid butterflyfishes of the genus Chaetodon from the central and western Pacific. Rec. West. Aust. Mus. 6:3-26.

Randall, J. E., R. L. Pyle, and R. F. Myers. 2001. Three examples of hybrid surgeonfishes (Acanthuridae). Aqua (Armadale) 4:115-120.

Rocha, L. A., D. R. Robertson, J. Roman, and B. W. Bowen. 2005. Ecological speciation in tropical reef fishes. Proc. R. Soc. Lond. B Biol. Sci. 272:573-579.

Severns, M., and P. Fiene-Severns. 1993. Molokini Island-Hawaii's premier marine preserve. Pacific Islands Publishing, Ltd., Honolulu.

Thiel, M., L. Gutow, and J. D. M. Gordon. 2005. The ecology of rafting in the marine environment. I. The floating substrata. Oceanogr. Mar. Biol. Annu. Rev. 42:181264.
Thresher, R. E. 1984. Reproduction in reef fishes. T.F.H. Publications, Inc., Ltd., Neptune City, New Jersey.

Timmers, M., C. Kistner, and M. Donohue. 2005. Marine debris of the NWHI: Ghost net identification. University of Hawai' $i$ Sea Grant College Program UNIHISEAGRANT-AR-05-01.

Trivers, R. L. 1972. Parental investment and sexual selection. Pages 136-179 in B. Campbell, ed. Sexual selection and the decent of man. Aldine, Chicago.

Tyler, W. A., III. 1988. Spawning patterns in the Hawaiian sergeant, Abudefduf abdominalis (family: Pomacentridae). Pac. Sci. 42:136.

1992. The spatial and temporal dynamics of colonial nesting in the maomao, Abudefduf abdominalis (family: Pomacentridae). Ph.D. diss., University of Hawai'i at Mānoa, Honolulu. . 1995. The adaptive significance of colonial nesting in a coral-reef fish. Anim. Behav. 49:949-966.

Tyler, W. A., III., and F. G. Stanton. 1995. Potential influence of food abundance on spawning patterns in a damselfish, Abudefduf abdominalis. Bull. Mar. Sci. 57:610623.

Walters, C. K. 1967. Nest guarding behavior of the male maomao, Abudefduf abdominalis (Quoy and Gaimard). M.S. thesis, University of Hawai'i at Mānoa, Honolulu. 
